Opinion

\title{
Bhikkhu Vivekanand; Vipassyana Meditataion and his address as a guest of honour to the 8the SSARC Psychiatric Federation International Conference in Lumbini Nepal
}

\author{
Upadhyaya KD
}

Senior Psychiatrist, Kathmandu Model hospital \& Advisor, CMC-Nepal

E-mail *Corresponding author: drkapilupadhyaya@gmail.com

\section{INTRODUCTION}

8th SSARC Psychiatric Federation International Conference was held on 27th to 29th November 2014, in Lumbini Nepal. Bhikkhu Vivekanad who is the resident meditation teacher at Panditarama Lumbini International Vipassana Meditation Center, was invited as a Guest of Honor in the inaugural session of our conference on 27th November 2014. The conference was held in the compound of Hotel Hokke . Our conference theme was: GLOBAL PEACE : TO NURTURE A HEALTHY MIND . Ven. Vivekanand in his address to the conference delegates, spoke about the mind from Buddhist Perspectives. He also spoke about the Vipassana meditation and its role for the healthy mind. His speech was very enlightening but because of time constraint we could not listen it fully. On my request, he kindly gave me time to listen to him and talk to him on the last day of the conference. The following summary is based on those two sessions.

Mindfulness meditation, Insight meditation or Vipassana meditation means the same meditation. Mindfulness means you have to be mindful in each and every activities that you do in waking hours for example brushing your teeth, walking, sitting, standing ,eating, opening and closing eyes etc. Try to do every activity slowly with mindfulness practice. By such mindfulness practice mind becomes more focused, ability to concentrate increases, intuitive knowledge ( Prazya) arises which is not an ordinary knowledge like knowledge by reading books. Physical form of our body is called form (rupa) and mental phenomena is called name (nama). Suppose you have pain in one part of the body - observe the pain, its type like burning, pricking, shooting etc and also observe its intensity like increasing or decreasing. Observe what truly occurs in body and in mind, which is knowing through direct observation. This is observing phenomenology using mental faculties.

Mental states can be wholesome mental states for example loving kindness, compassion etc and can be unwholesome mental states for example anger, hatred, greed which increase our sufferings. By Mindfulness practice mental purification increases thereby increasing wholesome mental states.

When intuitive knowledge increases equanimity manifests that is not reacting to anger or loving kindness, pleasurable or painful conditions and there is no agitation. This increases wholesome mental states. In retreat practice very little unwholesome mental state arise, there is clarity of mind, joyfulness is there, mindfulness becomes very sharp, very little thinking is there and if there is thinking, mindfulness immediately catches such thinking.

Mindfulness increases wisdom, intuitive thinking, energy, concentration, joy, upechha and tranquility known as the 7 enlightenment factors.

With mindfulness practice in retreat one can reach outstanding states of mind, once this experience is there, person knows the great state of mind/ mental health so that nothing 
disturbs the mind and nothing affects the mind. Spiritual stamina increases which is often called Teflon mind, that is nothing sticks to the mind. With mindfulness practice there is high degree of resilience power. After mindfulness practice in retreat for certain period one can experience as if one is floating in the sky or walking in the clouds.

As regards the role of mindfulness practice in mental disorders, mindfulness practice reduces relapse rate of depression by 40 percent. Depression can be cleared up with ordinary mindfulness practice.

Mindfulness practice while doing physical work like chopping wood, washing clothes, walking meditation for about an hour and sitting meditation are all beneficial. He said that there are 5 hindrances - sense desire, ill will, sloth and torpor, restlessness and skeptical doubts. Suffering increases because of all these hindrances.

When I asked him, what is the role of mindfulness practice in the management of anxiety disorders or the clients who come to us with different kinds of fear like fear of death, fear of going crazy or fear of serious physical illness he said- face the fear with mindfulness practice and handle with positive attitude - which disintegrates fear and dissolution of fear occurs. Fear of death is the fear of self which is just a concept as there is no self. Ordinary fear is due to impurity of conduct, excessive anger etc. He advised to focus the fear with mindfulness, focus on the distinct physical symptoms. For example if mindfulness is practiced during walking there is no opportunity to the fear to come in the mind. So he advised to practice walking meditation with mindfulness, body gets exhausted and fear subsides.

In a question, how to overcome psychological pain of different types of abuses, he said that the memory of abuse is the main factor here which is painful. He advised to practice mindfulness bring memory of abuse for brief period that distract the mind to something else so that the pain does not increase. One can distract the mind by reading a book or go walking with mindfulness. Same procedure can be repeated with slight increase in time everyday to lessen the pain. By such repeated practice with mindfulness, memory of abuse or the pain that it gives lessens gradually. Of course it is not so easy and it takes time. Over time hatred towards abuser, becomes less.

If Loviing kindness meditation is practiced, though it is difficult to direct to such people ( abuser), if practiced helps by breaking the barrier and transforming hatred to loving kindness.

Bhikku Vivekanand has translated and edited a book; BEAUTIFYING THE MIND: THE BUDDHA'S TEACHINGS ON EFFORT: by Sayadaw U. Pandita Some excerpt from the book"Effort, mindfulness and concentration possess, essential qualities that protect and defend the mind against the mental defilements and opens the road for the arising of wholesomeness. Mindfulness protects against mental defilements entering into the stream of consciousness; concentration suppresses the mental defilements. In being protected against lust, ill-will and delusion, the mind is secure...........When there is freedom from bondage there is peace, and that peace is a cause for genuine happiness. ${ }^{1}$

\section{REFERENCE}

1. Beautifying the mind: the buddha's teachings on effort: by Sayadaw $u$. pandita, Translated and edited by Bikkhu Vivekananda 